\title{
Biodeterioration patterns found in dammar resin used as art material
}

\author{
Julio Romero-Noguera* \\ Facultad de Bellas Artes \\ Universidad de Granada \\ Avda. Andalucía s/n \\ 18014 Granada, Spain \\ E-mail: juliorn@ugr.es
Facultad de Ciencias
Universidad de Granada
Avda. Fuentenueva
18071 Granada, Spain \\ Inés Martín-Sánchez \\ María del Mar López-Miras \\ Facultad de Bellas Artes \\ Universidad de Granada \\ Avda. Andalucía s/n \\ 18014 Granada, Spain \\ José Miguel Ramos-López \\ Centro de Instrumentación Científica \\ Campus Fuentenueva \\ 18071 Granada, Spain \\ Fernando Bolívar-Galiano \\ Facultad de Bellas Artes \\ Universidad de Granada \\ Avda. Andalucía s/n \\ 18014 Granada, Spain
}

Financial support: This study was supported by the National Spanish Project "I+D+I MCYT" CTQ2005-09339-C03-03.

Keywords: bacteria, biodeterioration, dammar, fungi, GC-MS.

Since the middle of the XIX century, when dammar became popular in Occident, this natural resin is one of the most used in art painting techniques as final protective coating (varnish) as well as a component of pictorial media. The present work is the first approach to the study of the microbiological biodeterioration of this artistic material, which can seriously affect the appearance and integrity of works of art when bad conservation conditions -especially high humidity levelstake place. 12 microorganisms, fungi and bacteria, came from collection and from oil paintings affected by biodeterioration patterns, were inoculated on test specimens prepared with varnish dammar. These were incubated and analyzed by GC-MS to determine both the microbiological capacity of growth and chemical alteration on the resin. Some of the studied microorganisms have shown patterns of deterioration similar to those found in works dedicated to natural or accelerated photochemical ageing of triterpenoid varnishes.
Dammar varnish is obtained from resins ("dammar" in Malayan) originated by adult trees belonging to the family of the Dipterocarpaceae -chiefly the species Hopea and Shorea- although more than 300 producing species have been described. Dammar-type resins are composed (Figure 1) mainly of tetracyclic triterpenoids of the dammarane series (dammaradienol, dammaradienone, and dammarenolic acid), as well as a lesser amount of pentacyclic triterpenoids derived from oleanane (oleanonic acid) and ursane, such as ursonic acid and ursonaldehyde (Masschelein-Kleiner, 1992; Mills and White, 1999). Van Aarssen et al. (1990) have described a little apolar fraction, composed of a hydrocarbonated polymer named $\beta$-resene.

The present work is aimed to expand the knowledge about the microbiological biodeterioration of this artistic material, which has not been studied to date, in spite of its potential importance in works of art subjected to bad conditions of conservation, especially long exposures to high levels of relative humidity. These processes can produce important

*Corresponding author 


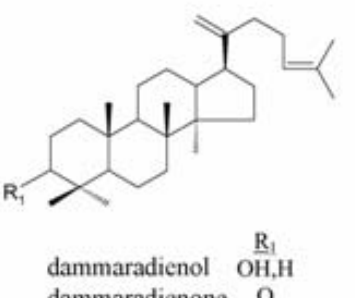

dammaradienone $\mathrm{O}$
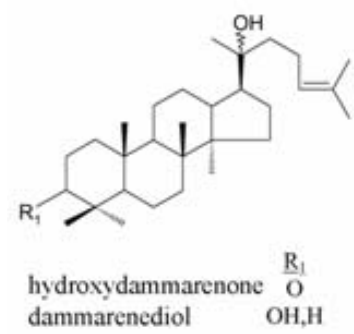

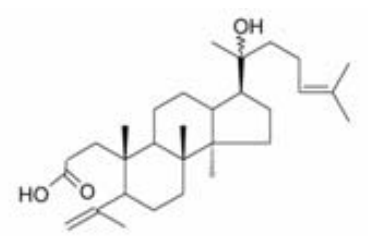

dammarenolic acid

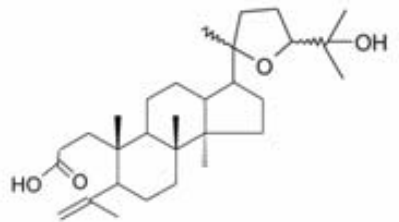

20,24-epoxy-25-hydroxy-3,4-seco-4(28)dammaren-3-oic acid

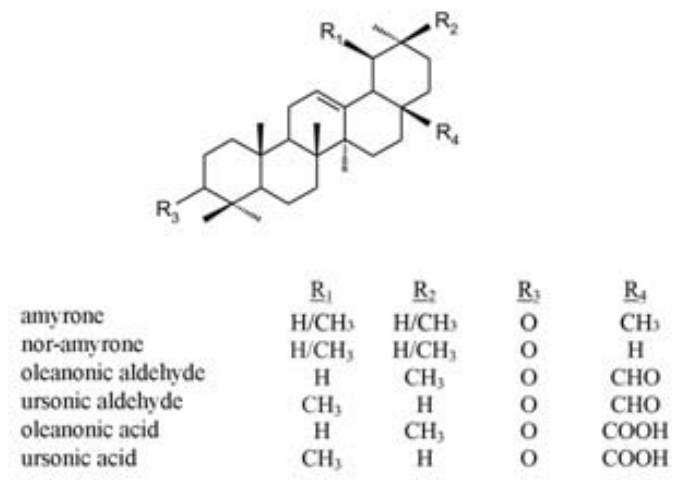

Figure 1. Scheme showing the main triterpenoid compounds described in dammar.

damages on natural varnishes that affect the visual appearance of works of art, such as changes of coloration, microcrak patterns, opacifications and even the disintegration of the protective and pictorial layers (Doménech-Carbó et al. 2006, Romero-Noguera et al. 2008).

With this purpose, fungi and bacteria, came from collection and from oil paintings affected by biodeterioration, were inoculated on test specimens prepared with varnish dammar. These were incubated and analyzed by GC-MS to determine both the microbiological capacity of growth and chemical alteration on the resin.

The only previous related information is an initial study on the biodeterioration of a mastic type resin (rather different in composition respect to dammar studied here) published by our research team (Doménech-Carbó et al. 2006). Test specimens prepared with mastic were inoculated with fungal mycelia came from collection strains. The chemical study was performed by GC-MS before derivatization with methyl chloroformate and some chemical changes, rather scattered, were described, as will be commented later.
In contrast, analytic studies of naturally aged triterpenoid varnishes from paintings (Van der Doelen et al. 1998b; Colombini et al. 2000) and of resins exposed to accelerated photoageing processes (Van der Doelen, 1998a; Van der Doelen and Boon, 2000) have been published. Oxidative patterns that affect to dammarane-type molecules (tetracycles) and oleanane/ursane ones (pentacycles) have been described. Dammaranes oxidized primarily on the double bonds of side chain, leading to hydroxyl groups that developed into epoxidic or lactonic structures in aged resins. Pentacycles of the oleanane/ursane type (minority in dammar) oxidize on C-17, C-11 and chiefly in C-28 (Van der Doelen et al. 1998a; Van der Doelen and Boon, 2000). These alterations are closely related with the yellowing and the increasing of fragility which results in microcrack and macrocrack patterns, as well as an augment in polarity and changes in solubility.

On the other hand, studies performed by GC-MS show that the total quantity of triterpenoids decreases over time because cleavage reactions, which produce the loss of the oleanane/ursane structure, whereas the fraction of high molecular weight products increases (Van der Doelen and 
Table 1. List of compounds corresponding to the marked peaks in Figure $3(\mathrm{Mw}=$ molecular weight; ID $=$ Identification; $\mathrm{L}=$ Wiley Mass Spectra Library; $\mathbf{R}=$ References).

\begin{tabular}{|c|c|c|c|}
\hline $\mathbf{N}^{\circ}$ & Compound & Pm & ID \\
\hline 1 & nor- $\beta$-amyrone & 410 & $\mathrm{R}$ \\
\hline 2 & nor-a-amyrone & 410 & $\mathrm{R}$ \\
\hline 3 & Dammaradienol & 426 & $\mathrm{R}$ \\
\hline 4 & Dammaradienone & 424 & $\mathrm{R}$ \\
\hline 5 & Hydroxydammarenone & 442 & $\mathrm{R}$ \\
\hline 6 & dammarenolic acid, methyl ester & 472 & $\mathrm{R}$ \\
\hline 7 & $\begin{array}{l}\text { 20,24-epoxy-25-hydroxy-3,4-seco-4(28)- } \\
\text { dammaren-3-oic acid, methyl ester }\end{array}$ & 488 & $\mathrm{R}$ \\
\hline 8 & oleanonic aldehyde & 438 & $\mathrm{R}$ \\
\hline 9 & oleanonic acid, methyl ester & 468 & $\mathrm{~L}$ \\
\hline 10 & ursonic aldehyde & 438 & $\mathrm{R}$ \\
\hline 11 & ursonic acid, methyl ester & 468 & $\mathrm{R}$ \\
\hline 12 & Hydroxyhopanone & 442 & $\mathrm{R}$ \\
\hline
\end{tabular}

Boon, 2000). These substances are found to be less soluble in common solvents used by painting restorers for varnish removal with the result that the layer of paint can be damaged if cleaning work is needed.

\section{MATERIALS AND METHODS}

\section{Varnish}

The varnish used was first quality white dammar, supplied by Caremi Pigmentos (Sevilla, España). It was dissolved in purified turpentine essence, supplied by Titan (Barcelona, Spain), in the proportion of $175 \mathrm{~g}$ of resin per $300 \mathrm{ml}$ of turpentine essence (Mayer, 1991).

\section{Microorganisms}

The microorganisms used in the experiments were selected after reviewing the literature on biodeterioration of wall and easel painting (Ciferri, 1999; Garg et al. 1995; Arai, 2000; Doménech-Carbó et al. 2006; Romero-Noguera et al. 2008, among others). They came from stock collections belonging to the Spanish Collection of Type Cultures (CECT, Colección Española de Cultivos Tipo, Universidad de Valencia, Valencia, Spain). The microorganisms used were:

Arthrobacter oxydans (Ao) (CECT-386, ATCC 14358), Bacillus amyloliquefaciens (Ba) (CECT-493, ATCC
23842), Streptomyces celluloflavus (Sc) (CECT-3242, ATCC 29806), Aspergillus niger (An) (CECT-2088, ATCC 9029), Aureobasidium pullulans (Au) (CECT-2703, ATCC 9348), Cladosporium cladosporioides (Cc) (CECT 2110, ATCC 16022), Penicillium chrysogenum (Pc) (CECT2306, ATCC 8537), Rhizopus oryzae (Ro) (CECT-2339, ATCC 11145), Mucor rouxii (Mr) (CECT-2655, ATCC 24905) and Trichoderma pseudokoningii (Tp) (CECT2937).

The study also includes the fungi Phoma herbarum and Chrysonilia sitophila, identified by CECT and isolated from surface of oil on canvas paintings of the Fine Arts Museum of Granada (Spain) entitled Allegory of Death (by P. Toma) and St. Francis of Assisi (anonymous), both of the $17^{\text {th }}$ century and severely affected by biodeterioration processes.

\section{Test specimens preparation}

Glass slides of standard size (24 x $80 \mathrm{~mm})$, covered with dammar were used as test specimens. The varnish was applied by brush in three successive layers $(0.5 \mathrm{~mm}$ thickness). The specimens were dried in darkness at room temperature for 90 days. These supports imitate a varnished surface, and avoid the possible interferences produced by organic materials present in works of art. 

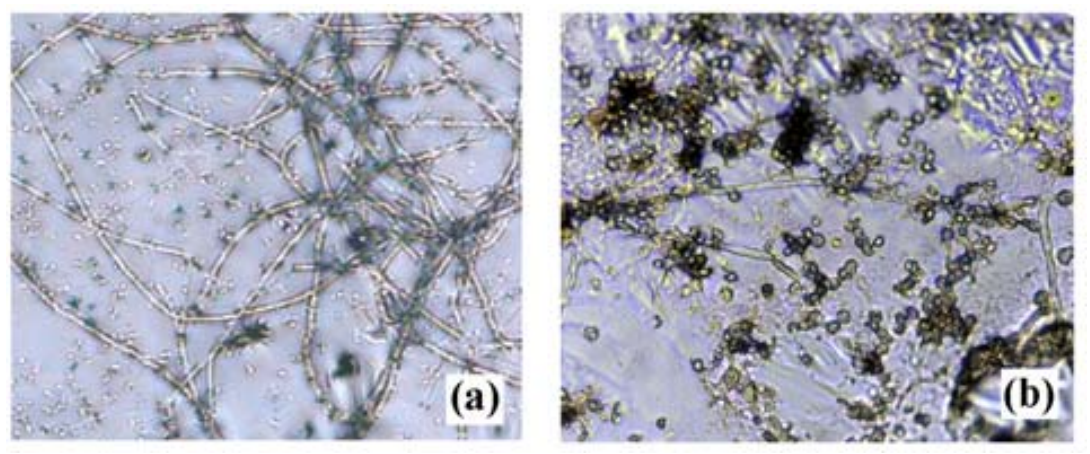

Figure 2. Microphotographs $(400 x)$ showing the fungal growth after 5 days of incubation of (a) $P$. herbarum, (b) $P$. chrysogenum.

To obtain fungal spores, lyophilized collection stocks were hydrated in malt extract broth (Oxoid) and incubated for one week. Afterwards, cultures were spread on malt extract agar (Oxoid) medium and incubated for 15 days. Sporulated cultures were resuspended in $2 \mathrm{ml}$ of Tween 80 $0.1 \%$ (Aldrich). After centrifugation, pellets were washed and resuspended in $2 \mathrm{ml}$ of distilled water. The suspensions were filtered through glass wool to eliminate any remains of mycelium. After a count in a Neubauer chamber, the concentration was adjusted to $10^{6}$ spore $\mathrm{ml}^{-1}$.

Bacterial suspensions $\left(10^{7}-10^{8}\right.$ cells $\left.\mathrm{ml}^{-1}\right)$ were used for bacteria cultures, after centrifugation and washing with distilled water to eliminate any possible remains of culture media (Tryptone Soya Broth-TSB, Oxoid). Finally, fungi and bacteria were inoculated on supports with several drops $(75 \mu \mathrm{l})$ of, respectively, spore or bacterial suspensions described above. Previous experiments helped us to establish the optimal conditions for incubating the model varnish specimens. The specimens were incubated for 15 days in darkness at $28^{\circ} \mathrm{C}$ and $85-90 \% \mathrm{RH}$, water activity $\left(\mathrm{a}_{\mathrm{w}}\right)=0.85$.

\section{Instrumentation and procedures}

A sterile scalpel was used to scrape the samples from the test specimens, providing about $0.5 \mathrm{mg}$ per sample. These were dissolved in $25 \mu \mathrm{l}$ of benzene. Then, $25 \mu \mathrm{l}$ of (mtrifluoro-methylphenyl) trimethylammonium hydroxide (Meth Prep II, Alltech) were added. The reaction mixture was shaken for about $40 \mathrm{~min}$ at room temperature. $1 \mu \mathrm{l}$ of the sample solution was injected into the GC. Analyses were carried out using a Platform II mass spectrometer (Micromass Instruments, UK) coupled to a Carlo Erba 8060 gas chromatograph (Thermo Instruments, USA). Chromatographic separations were achieved on a fusedsilica capillary column (HP-1MS), $(100 \%$ dimethylpolysiloxane), $30 \mathrm{~m} \times 0.25 \mathrm{~mm}$ I.D. and $0.25 \mu \mathrm{m}$ film thickness. The chromatographic conditions for the GCMS analysis were: injector temperature $=250^{\circ} \mathrm{C}$, transfer line temperature $=300^{\circ} \mathrm{C}$, oven temperature $=120^{\circ} \mathrm{C}(2$ $\mathrm{min}), 10^{\circ} \mathrm{C} / \mathrm{min}$ to $300^{\circ} \mathrm{C}$ then isothermal for $20 \mathrm{~min}$. The carrier gas was helium at a flow-rate of $1.2 \mathrm{~mL} / \mathrm{min}$. Samples were injected in splitless mode. Mass spectra were performed in total ion monitoring mode (mass range 50-550 $\mathrm{m} / \mathrm{z}$ ) and ions were generated by electron impact ionisation $(70 \mathrm{eV})$. The source temperature was $210^{\circ} \mathrm{C}$. A MassLynx v.4.0 data system was used for data acquisition and processing and the peak area (TIC) data were used to obtain peak area percentage value.

Calculations were based on values of the normalized peak area $N i$, defined as the percentage of peak area of each individual compound relative to the set of peak areas of the $n$ components found in the model varnish:

$N_{i}=\frac{A_{i}}{\sum_{i=1}^{n} A_{i}} \times 100$

where $A i$ is the peak area of each of the $n$ compounds found in the chromatogram. Blank samples, inoculated with distilled water and incubated under on the same conditions as those of the samples inoculated with microorganisms, were also analysed to evaluate the composition of studied varnishes in the absence of microorganisms. The changes in the composition were determined by establishing a $\Delta \mathrm{Ni}$ parameter, defined as the increase or decrease in $\mathrm{Ni}$ for each analyte in relation to the values corresponding to the blank sample $N_{i o}$.

$\Delta N i=N_{i}-N_{i o}$

A total of three replicates for each sample were used. The values considered for results were the average of the triplicate groups. The repeatability found under the experimental conditions and the relative standard deviations-calculated using the formula $\mathrm{RSD}=($ standard deviation/mean of the normalized peak area) x $100 \%$ - fell within the range $1-5 \%$ for all the compounds analysed. The Student's t-test was used for comparison of the differences between means values of inoculated and non inoculated (blank) samples. Only the values with a $P<0.05$ were considered statistically significant. 
Table 2. GC-MS analysis ( $P<0.05$ in all cases) of tetracyclic* triterpenoids of blank sample (in bolds), and samples inoculated with microorganisms (Average values expressed in $\mathrm{Ni}$ (in bolds) and $\Delta \mathrm{Ni}$ ).

\begin{tabular}{|l|c|c|c|c|c|}
\hline & $\begin{array}{c}\text { dammaradienone } \\
\text { nor- } \beta \text {-amyrone* }\end{array}$ & dammaradienol & $\begin{array}{c}\text { ocotillone type } \\
\text { comp. }\end{array}$ & $\begin{array}{c}\text { dammarenolic } \\
\text { acid }\end{array}$ & $\begin{array}{c}\text { OH- } \\
\text { dammarenone }\end{array}$ \\
\hline & $\mathbf{3 . 3 4}$ & 1.92 & $\mathbf{0 . 7 0}$ & $\mathbf{1 6 . 3 3}$ & $\mathbf{5 5 . 8 1}$ \\
\hline Fungi & -1.05 & -0.55 & +0.5 & -3.48 & -5.13 \\
\hline C. sitophila & -1.11 & -1.03 & +6.92 & +7.02 & -20.13 \\
\hline P. chrysogenum & -0.41 & -0.75 & +1.23 & +2.18 & -11.14 \\
\hline P. herbarum & -2.31 & -0.70 & +1.02 & +4.91 & -9.58 \\
\hline Bacteria & +1.04 & +0.77 & +0.85 & +0.88 & -6.61 \\
\hline A. oxydans & +0.57 & +0.99 & +1.10 & +9.12 & -14.95 \\
\hline B. amyloliquefaciens & & & & & \\
\hline S. celluloflavus & & & & \\
\hline
\end{tabular}

*nor- $\beta$-amyrone is a pentacyclic compound

\section{RESULTS AND DISCUSSION}

\section{Control of fungal growth}

The evolution of fungal cultures was monitored by surveillance photography of colonial morphology at 0,24 hrs, 48 hrs, 5, 10 and 15 days with a Nikon Eclipse TS100 microscope equipped with a Nikon DS-5M digital camera. Three fungi, C. sitophila, $P$. chrysogenum and $P$. herbarum were found to growth on test specimens at 5 days of incubation (Figure 2). In no case were significant changes detected after the 5 days of incubation. The varnishes underwent important visual damages, such as micro and macro fissures as well as tonality changes.

\section{Gas chromatography/mass spectrometry}

The Figure 3 shows the region of triterpenoids of the TIC of dammar after derivatization with Meth-Prep II. The labels for the peaks are explained in Table 1. The compounds were identified according to the database (Table 1, L) of the Wiley Mass Spectra Library, and the mass spectra published (Table 1, R) in the literature (Van der Doelen et al. 1998a, Van der Doelen et al. 1998b; Van der Doelen and Boon, 2000; Assimopoulou and Papageorgiou, 2005a; Assimopoulou and Papageorgiou 2005b). Dammaradienone characterized by main peaks at $\mathrm{m} / \mathrm{z}=424,205$, 109, was eluted together with nor- $\beta$ amyrone $(\mathrm{m} / \mathrm{z}=410,204)$.
The analytical results are shown in Table 2, Table 3, Figure 3 and Figure $4(P<0.05$ in all cases). The blank sample (not inoculated with microorganisms) presented high values of tetracyclic triterpenes hydroxydammarenone $(\mathrm{Ni}=$ $55.81 \%)$, dammarenolic acid $(N i=16.33 \%)$, dammaradienol, dammaradienone and, to a lesser extent, pentacyles nor- $\alpha$-amyrone nor- $\beta$-amyrone, and oleanonic and ursonic acids. Similar results were found in the case of two additional control samples inoculated with inactivated spores (A. niger) and bacteria (A. oxydans).

The most important changes were reported in $P$. chrysogenum, consisting in a strong increase in the relative quantity of dammarenolic acid $(\triangle N i=7.02)$ and the ocotillone type compound $(\Delta N i=6.92)$, as well as an important decrease in the relative amount of hydroxydammarenone $(\Delta N i=-20.13)$. The augment in 20,24-epoxy-25-hydroxy-3,4-seco-4(28)-dammaren-3-oic acid, very probably caused by the oxidation of the lateral chain of dammarenolic acid, is a clear indication of deterioration caused by this microorganism, considering that oxidized ocotillon type compounds were described like important markers of the deterioration of dammar in studies on accelerated photoaging (UV) treatments. The formation of these substances, more polar than the original ones, is an important factor which explains alteration processes such as the yellowing and the increasing of fragility which results in microfissures and leaching patterns (Van der Doelen et 


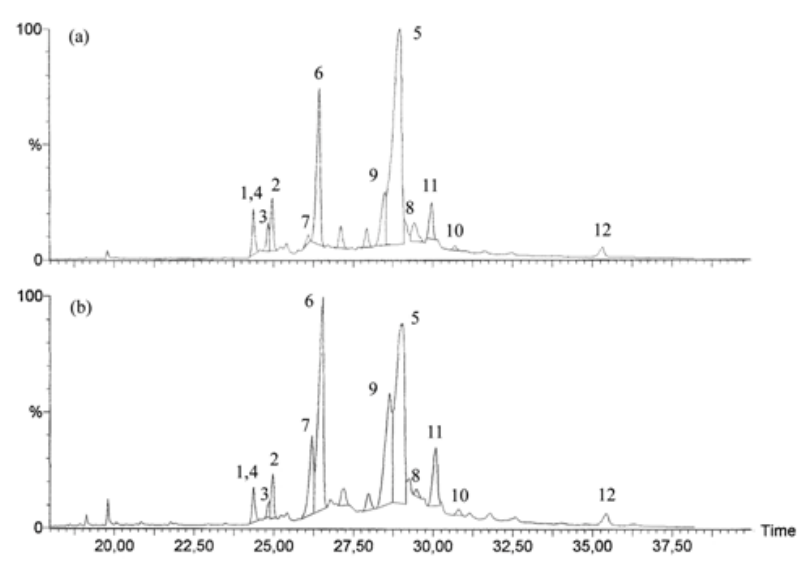

Figure 3. Chromatograms corresponding to: (a) dammar varnish blank sample (b) dammar varnish inoculated with $P$. chrysogenum. Labels are explained in Table 1.

al. 1998a). In fact, micro and macro fissures, as well as changes in opacity, were clearly observed in these samples.

The notable reduction in hydroxydammarenone could be explained by the formation of either polymerized or low molecular weight products, both non detectable by GC-MS and so not found in the chromatogram. This pattern of deterioration has been described in the composition of aged varnishes, in which the amount of free triterpenoids decreases with time and therefore leading to the insolubility of the resinous layer (Van der Doelen et al. 1998a). A similar trend was also observed in others microorganisms studied in the present work, as well as in the only study published on biodeterioration of triterpenoid resins, made by our team of investigation, using mycelia (non spores, as in this case) of $P$. chrysogenum inoculated on mastic varnish (Doménech-Carbó et al. 2006), which suggests this compound is the most susceptible to undergo biodeterioration processes of whatever integrate triterpenoid resins.

In regards to the rest of the fungi, $P$. herbarum showed a similar trend, although less accentuated, with a decrease in hydroxydammarenone $(\triangle N i=-11.14)$ and a slight increase of the above-mentioned compounds. C. sitophila showed minor changes with respect to the non-inoculated control, except for a slight global decrease in tetracyclic compounds in favour of the pentacyclic ones, which suggests a smaller biological activity of this microorganism on the studied varnish. On samples inoculated with bacteria, $S$. celluloflavus showed the most important changes, similar to those found in $P$. chrysogenum, with an important decrease of hydroxydammarenone $(\Delta N i=-14.95)$ as well as a correlative rise of the most stable compounds: the acids dammarenolic and oleanonic. The great augment of the ocotillone-type compound was not reported. The analytical results tended to be similar in the other two bacteria, though less marked.
In the pentacyclic triterpenoid fraction (Table 3), similar changes were observed for the three fungi: a clear increase in the relative amount of the most stable compounds: ursonic and chiefly oleanonic acids, the latter reaching a $\Delta N i$ of around +10 , explained by the degradation of tetracyclic triterpenoids, like hydroxydammarenone. Other minor changes detected were a slight decrease of noramyrone and the small peak corresponding to oleanonic aldehyde. Bacteria reported similar trends to that found on fungi, although less clear. Amyrone derivatives remained, whereas the relative amount of both oleanonic $(\Delta N \mathrm{Ni}=+8.17$ in $A$. oxydans) and ursonic acids, increased in all of bacterian samples, except in $S$. celluloflavus, that kept the rate of the latter compound. The only hopanic compound, hydroxyhopanone, showed no significant changes in any of the cases.

The present results resemble with those found in works dedicated to natural or artificial ageing (by radiation) of filmogenic triterpenic materials, suggesting that some microorganisms favour natural deterioration processes of dammar varnish. These works report that dammaranes oxidize primarily on the double bonds of side chain, leading to hydroxyl groups that developed into epoxidic or lactonic structures in aged resins (Van der Doelen et al. 1998a; Van der Doelen et al. 1998b; Van der Doelen and Boon, 2000). Although in no case were alterations as pronounced as those previously described, this was to be expected, given that these studies were made under much more drastic conditions (long UV exposure, liquid medium, very ancient resins) than those chosen for the present work. On the other hand, we assume that the capacity of survival of the microorganisms in such a hostile medium should be low. Nevertheless, under real biodeterioration conditions, whit high moisture levels and constant influx of new microorganisms and organic matter came from the surroundings, is possible to expect greater changes respect to those observed in the present study.

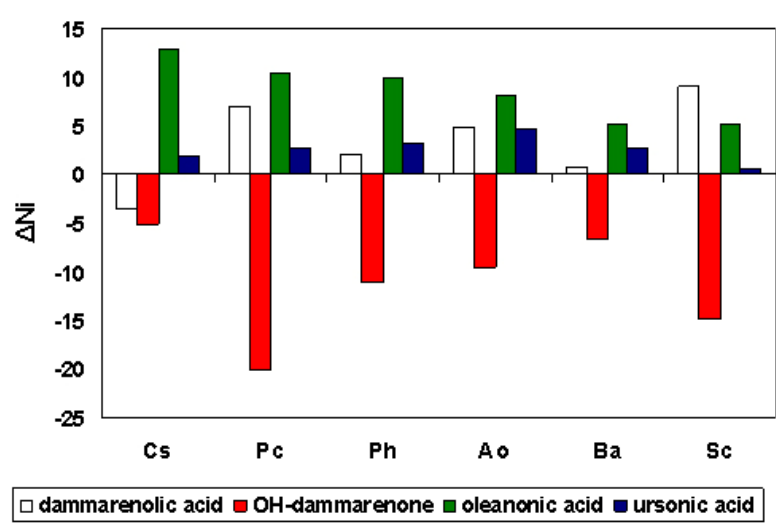

Figure 4. GC-MS analysis ( $\triangle \mathrm{Ni}$ values) of dammar samples inoculated with microorganisms. $(\mathrm{Cs}=$ C. sitophila; $\mathrm{Pc}=P$. chrysogenum; $\mathrm{Ph}=P$. herbarum; $\mathrm{Ao}=A$. oxydans; $\mathrm{Ba}=B$. Amyloliquefaciens; $\mathrm{Sc}=\mathrm{S}$. celluloflavus). 
Table 3. GC-MS analysis $(P<0.05$ in all cases) of pentacyclic triterpenoids of blank sample (in bolds), and samples inoculated with microorganisms (Average values expressed in $\mathrm{Ni}$ (in bolds) and $\Delta \mathrm{Ni}$ ).

\begin{tabular}{|c|c|c|c|}
\hline & nor- $\alpha$-amyrone & oleanonic acid & ursonic acid \\
\hline & 4.25 & 6.67 & 3.57 \\
\hline \multicolumn{4}{|c|}{ Fungi } \\
\hline C. sitophila & +0.46 & +12.91 & +1.86 \\
\hline P. chrysogenum & -1.54 & +10.54 & +2.69 \\
\hline P. herbarum & -1.29 & +9.99 & +3.20 \\
\hline \multicolumn{4}{|c|}{ Bacteria } \\
\hline A. oxydans & -1.76 & +8.17 & +4.78 \\
\hline B. amyloliquefaciens & -0.26 & +5.16 & +2.84 \\
\hline S. celluloflavus & +0.08 & +5.15 & +0.59 \\
\hline
\end{tabular}

\section{CONCLUDING REMARKS}

Spores of three of the studied fungi (C. sitophila, $P$. chrysogenum and $P$. herbarum) were able to germinate onto the studied varnish. The main chemical changes in samples in which fungal growth was detected were observed in $P$. chrysogenum, and resemble the ones observed in processes of accelerated photoageing, emphasizing an appreciable increase of an oxidized derivative ocotillone-type, as well as an important reduction of the relative amount of hydroxydammarenone. The pentacyclic components showed a great stability in the experimental conditions of the study. The rest of the studied fungi and bacteria, especially $S$. celluloflavus, registered similar tendencies, although less marked.

\section{REFERENCES}

ARAI, Hideo. Foxing caused by fungi: twenty-five years of study. International Biodeterioration \& Biodegradation, October 2000, vol. 46, no. 3, p. 181-188.

ASSIMOPOULOU, A.N. and PAPAGEORGIOU, V.P. GC-MS analysis of penta- and tetra-cyclic triterpenes from resins of Pistacia species. Part I. Pistacia terebinthus var. Chia. Biomedical Chromatography, May 2005, vol. 19, no. 4, p. 285-311.

ASSIMOPOULOU, A.N. and PAPAGEORGIOU, V.P. GC-MS analysis of penta- and tetra-cyclic triterpenes from resins of Pistacia species. Part II. Pistacia terebinthus var. Chia. Biomedical Chromatography, October 2005, vol. 19, vol. 8, p. 586-605.
CIFERRI, Orio. Microbial degradation of paintings. Applied and Environmental Microbiology, March 1999, vol. 65 , no. 3 , p. $879-885$.

COLOMBINI, M.P.; MODUGNO, F.; GIANNARELLI, S.; FUOCO, R. and MATTEINI, M. GC-MS characterization of paint varnishes. Microchemical Journal, December 2000, vol. 67 , no. 1-3, p. 385-396.

DOMÉNECH-CARBÓ, María Teresa; OSETE-CORTINA, Laura; DE LA CRUZ-CAÑIZARES, Juana; BOLÍVARGALIANO, Fernando; ROMERO-NOGUERA, Julio; FERNÁNDEZ-VIVAS, María Antonia and MARTÍNSÁNCHEZ, Inés. Study of the microbiodegradation of terpenoid resin-based varnishes from easel painting using pyrolysis-gas chromatography-mass spectrometry and gas chromatography-mass spectrometry. Analytical and Bioanalytical Chemistry, August 2006, vol. 385, no. 7, p. 1265-1280.

GARG, K.L.; KAMAL, K.J. and MISHRA, A.K. Role of fungi in the deterioration of wall paintings. Science of the Total Environment, May 1995, vol. 167, no. 1-3, p. 255271.

MASSCHELEIN-KLEINER, L. Liants, vernis et adhésifs anciens. Bruxelles; Institut Royal du Patrimoine Artistique, 1992. 123 p. ISBN 2-930054-01-08.

MAYER, R. The artist's handbook of materials and techniques. New York; Penguin books, 1991. 713 p. ISBN 0-670-83701-6. 
MILLS, John S. and WHITE, Raymond. The organic chemistry of museum objects. $2^{\text {nd }}$ ed. Oxford; ButterworthsHeinemann, 1999. 206 p. ISBN 0-7506-1693-8.

ROMERO-NOGUERA, J.; BOLÍVAR-GALIANO, Fernando C.; RAMOS-LÓPEZ, J.M.; FERNÁNDEZVIVAS, María Antonia and MARTÍN-SÁNCHEZ, Inés. Study of biodeterioration of diterpenic varnishes used in art painting: Colophony and Venetian turpentine. International Biodeterioration \& Biodegradation, December 2008, vol. 62 , no. 4, p. 427-433.

VAN AARSSEN, B.G.K.; COX, H.C.; HOOGENDOORN, P. and DE LEEUW, J.W. A cadinene biopolymer present in fossil and extant dammar resins as a source for cadinanes and bicadinanes in crude oils from South East Asia. Geochimica et Cosmochimica Acta, November 1990, vol. 54, no. 11, p. 3021-3031.

VAN DER DOELEN, Gisela A. and BOON, Jaap Jan. Artificial ageing of varnish triterpenoids in solution. Journal of Photochemistry and Photobiology A: Chemistry, June 2000, vol 134, no. 1-2, p. 45-57.

VAN DER DOELEN, Gisela A.; VAN DEN BERG, Klaas J. and BOON, Jaap Jan. Comparative chromatographic and mass-spectrometric studies of triterpenoids varnishes: fresh materials and aged simples from paintings. Studies in Conservation, 1998a, vol. 43, no. 4, p. 249-264.

VAN DER DOELEN, Gisela A.; VAN DEN BERG, Klaas Jan; BOON, Jaap Jan; SHIBAYAMA, Nobuko; DE LA RIE, E. René and GENUIT, Wim J.L. Analysis of fresh triterpenoid resins and aged triterpenoid varnishes by highperformance liquid chromatography-atmospheric pressure chemical ionisation (tandem) mass spectrometry. Journal of Chromatography A, June 1998b, vol. 809, no. 1-2, p. 21-37. 